\title{
Oral healthcare in transition in Eastern
}

Europe

\author{
E. Widström, ${ }^{1}$ K. A. Eaton, ${ }^{2}$ A. Borutta, ${ }^{3}$ E. Dybizbánska ${ }^{4}$ and Z. Broukal ${ }^{5}$
}

\begin{abstract}
Big changes have occurred in the oral healthcare delivery systems of most Eastern European countries since the fall of the Berlin wall in 1989 and the demise of communism in the former USSR in 1991. In the new situation it was necessary to reform the political and social systems including healthcare. Reforms were started to improve the economy and, in comparison with Western Europe, the generally lower living standards. It is difficult to obtain comprehensive data on oral healthcare in Eastern European countries but this paper reports data from nine countries and provides a 'macro' view of the current situation in these countries. Many countries seem to have adopted a Bismarckian model for the provision of oral healthcare based on a sickness insurance system.
\end{abstract}

Traditionally, the government's role in organising and financing healthcare was strong in Eastern European countries, with central planning and rigorous control. Nearly all health workers, including dentists and physicians, were salaried employees of the state who worked in state-owned clinics. Oral healthcare was provided free of charge for all citizens. In the last decade, there has been a general privatisation and in many Eastern European countries, most dentists now work in independent private practice. However, the pace of privatisation has varied from country to country and was most rapid in Former Eastern Germany ${ }^{1}$.

${ }^{1}$ Associate Professor, Chief Dental Officer of Finland The National Research and Development Centre for Welfare and Health (STAKES), P.O. Box 220, 00531 Helsinki

${ }^{2}$ Senior Honorary Research Fellow, Eastman Dental Institute for Oral Healthcare Sciences, University College London, 256, Gray's Inn Road, London, WC1X 8TD, UK

${ }^{3}$ Professor, Department of Preventive Dentistry,

Friedrich-Schiller University of Jena, Nordhäuser

Strasse 78, 99089 Erfurt, Germany

${ }^{4}$ Academic Teacher, Department of Conservative

Dentistry, Medical University of Warsaw, 00-246

Warsaw, ul. Miodowa 18, Poland

${ }^{5}$ Associate Professor, Institute of Dental Research,

General Faculty Hospital, Department of Oral

Epidemiology and Preventive Dentistry, Vinohradska

48, 12060 Prague 2, Czech Republic

Correspondence to: Eeva Widström

*e-mail-eeva.widstrom@stakes.fi

REFEREED PAPER

Received 14.07.00; Accepted 19.09.00

(C) British Dental Journal 2001; 190: 580-584
In the European Union (EU) and European Economic Area (EEA), there is an underlying philosophy of free movement for the workforce. This philosophy is enshrined in Dental Training Directives 686/78/EEC and 687/78/EEC ${ }^{2}$, which require all $\mathrm{EU}$ and $\mathrm{EEA}$ member states to recognise primary and specialist training completed in the EU and EEA by EU and EEA nationals. Although the Training Directives imply harmonisation and convergence of training standards within the EU, membership of the EU does not require member states to modify their health or oral healthcare systems. These vary throughout the EU and EEA ${ }^{3}$. Nevertheless, it is desirable to be aware of the differences in oral healthcare systems between the present and future member states. This paper therefore reports data from a recent survey carried out on behalf of the Council of European Chief Dental Officers (CECDO $)^{4}$, supplemented by brief descriptions of the current systems for the provision of oral healthcare in the Czech Republic, Hungary and Poland. Data were received from nine Eastern European countries (Belarus, Bosnia, Bulgaria, Czech Republic, Hungary, Latvia, Lithuania, Poland and Slovenia). As far as possible the resulting data were checked by the authors through correspondence with alternative sources (dentists working in university departments and in dental public health appointments) and by comparing with existing reports.

\section{Increasing numbers of dentists}

Traditionally, oral healthcare has been provided by stomatologists in many Eastern European countries. In the former East Germany, Soviet Union, Poland, Bulgaria, CSSR and other Eastern European countries, a stomatologist provided the same range of care and treatment as dentists in Western Europe. However, their training was different and often included medical subjects such as obstetrics. Stomatologists were assisted by general (medical) nurses and in some countries there was very little four-handed dentistry. The ratio of stomatologists to nurses was therefore low. This tendency is reflected in the reported low numbers of dental nurses in relation to dentists (Table 1).

Bulgaria and the Czech Republic had the greatest numbers of dentists and technicians per 10,000 inhabitants. Four Eastern European countries reported higher numbers of dentists per 10,000 inhabitants than the EU/EEA mean. However, all countries reported considerably fewer technicians than the EU/EEA mean (Table 1), which suggests that less dentistry involving technical work took place. In the last 12 years the number of dentists increased in almost all countries, mostly in Slovenia (30\%) and in the Czech Republic (29\%). There was a dramatic fall in numbers of dentists/stomatologists in Bosnia between 1986 and 1988 which lost over half its dentists during the recent war. The increase of numbers of dentists does not necessarily reflect an increased output. In the Czech Republic the basic units of the past healthcare system were the 95 so-called District Centres of National Health. These were grouped in eight county centres and controlled by the Ministry of Health. Many dentists worked in this system as administrative dentists and did not practice dentistry. When the system was abolished in 1992, these dentists lost their administrative jobs and returned to clinical practice. During the 12-year period, the numbers of dentists in the EU and EEA rose by $15 \%$ (Table 2). Four countries reported that they did not have any dental hygienists, which was perhaps unsurprising as there were only 12,000 for a population of $378,000,000$ in the EU and EEA in $1996^{3}$. However, Latvia and Czech Republic have started training hygienists and Slovenia may well follow suit. 


\begin{tabular}{|c|c|c|c|c|}
\hline Table I & \multicolumn{4}{|c|}{$\begin{array}{l}\text { Numbers of dentists, technicians, hygienists and dental nurses per } 10,000 \text { inhabitants in } \\
\text { Eastern European countries in } 1998\end{array}$} \\
\hline Country & Dentists* & Technicians & Hygienists & Dental nurses (assistants) \\
\hline Belarus & 5.6 & 0.7 & No *** & No ** \\
\hline Bosnia & 1.8 & - & No ** & - \\
\hline Bulgaria & 8.5 & 3.6 & No ** & 6.2 \\
\hline Czech Republic & 7.1 & 4.4 & 0.03 & 7.1 \\
\hline Hungary & 4.0 & 2.2 & 0.15 & 4.2 \\
\hline Latvia & 6.9 & 2.2 & 0.2 & 1.4 \\
\hline Lithuania & 5.9 & 2.1 & 0.2 & 3.9 \\
\hline Poland & 4.6 & 1.3 & 0.6 & 1.8 \\
\hline Slovenia & 6.8 & 3.2 & No $* *$ & 4.3 \\
\hline Mean in $\mathrm{EEA}^{* * *}$ & 6.4 & 6.3 & - & - \\
\hline \multicolumn{5}{|c|}{$\begin{array}{l}\text { *Stomatologists included } \\
\text { **No such category } \\
\text { ***No information reported from Belgium, France and Spain (EEA mean calculated without including these countries) }\end{array}$} \\
\hline
\end{tabular}

\section{Data on oral health}

High DMFT-index values can still be found among 12-year-olds in Eastern Europe (Table 3). In 1996 most EU/EEA countries reported current DMFT values of between 1 and 2 with the highest value of 3.2 in Portu- $\mathrm{gal}^{3}$. Only Slovenia (1.8) reported achieving 'the EU/EEA-level'. During the last 10-12 years in four of the nine Eastern European countries the DMFT level in 12-year-olds appears to have deteriorated. Reported percentages of DMFT $=0$ (caries free) were gen- erally low (Table 3 ). There are many possible explanations for this situation. In EU and EEA countries improved oral health has been associated with improved living conditions and education, better oral hygiene and use of fluorides ${ }^{5,6}$. A recent study has suggested that

\section{Table 2 Numbers of dentists* in Eastern European countries in 1986 and 1998}

$\begin{array}{lccc}\text { Country } & 1998 & 1986 & \text { Percentage increase } \\ \text { Belarus } & 5800 & - & - \\ \text { Bosnia } & 639 * & 1346^{*} & -53 \\ \text { Bulgaria } & 7119 & 5745 & +24 \\ \text { Czech Republic } & 7350 & 5300 & +29 \\ \text { Hungary } & 4000 & 3200 & +25 \\ \text { Latvia } & 1685 & 1532 & +10 \\ \text { Lithuania } & 4259 & - & - \\ \text { Poland } & 17782 & 17440 & +2 \\ \text { Slovenia } & 1347 & 1039 & +30 \\ \text { Total in EEA in } 1996 & 240785 & 209597^{* *} & +15\end{array}$

* Stomatologists included

**Eurostat data with 12,500 added for the former East Germany and estimate of 32,000 for Italy 


\begin{tabular}{|c|c|c|c|c|}
\hline \multirow{2}{*}{$\begin{array}{l}\text { Table } 3 \\
\text { Country }\end{array}$} & \multicolumn{4}{|c|}{$\begin{array}{l}\text { Mean DMFT scores for I2-year-olds in } 1990 \text { and } 1998 \text { percentage of caries free and percentage } \\
\text { of edentulous 65-74-year-olds in Eastern European countries in } 1998\end{array}$} \\
\hline & $\begin{array}{l}\text { DMFT } \\
\text { 1990* }\end{array}$ & $\begin{array}{l}\text { DMFT } \\
1998\end{array}$ & $\begin{array}{l}\% \text { DMFT }=0 \\
1996 / 98\end{array}$ & $\begin{array}{l}\text { \% edentulous } \\
65-74-\text { year-olds }\end{array}$ \\
\hline Belarus & 3.3 & 3.8 & 5 & 12 \\
\hline Bosnia & $4.0-6.0 * *$ & 8.6 & - & 78 \\
\hline Bulgaria & 3.5 & 4.2 & 10 & 53 \\
\hline Czech Republic & 3.3 & 3.4 & 14 & 20 \\
\hline Hungary & 4.3 & 3.8 & 17 & 54 \\
\hline Latvia & 7.7 & 5.8 & 5 & - \\
\hline Lithuania & 3.9 & 4.9 & 8 & 39 \\
\hline Poland & 5.1 & 4.0 & 11 & 35 \\
\hline Slovenia & $4.0-6.0 * *$ & 1.8 & - & 22 \\
\hline \multicolumn{5}{|c|}{$\begin{array}{l}\text { *Data from WHO I986-199I } \\
\text { **Data for all Yugoslavia }\end{array}$} \\
\hline
\end{tabular}

tooth brushing frequency among youngsters is lower in Eastern than in Western Europe ${ }^{7}$. The Eastern European countries also ceased to supplement the levels of fluoride in their drinking water during the 1990s. However, the four countries due to join the EU plus Latvia, have all achieved improved DMFT levels in 12-year-olds over the last decade. Two of these countries (Latvia and Slovenia) have organised special preventive programmes, which include oral health education and fissure sealing ${ }^{8,9}$. Additionally, in the Czech Republic programs of oral health education in kindergartens and elementary schools were established in 1997 and are slowly expanding in number.

The range in the percentages of the population over the age of 65 years who were edentulousness was wide (Table 3 ). In the EU/EEA countries a similar range of from $17 \%$ (Sweden) to $72 \%$ (Portugal) has been reported ${ }^{10}$.

\section{Uptake and costs of oral healthcare services}

The data for utilisation of services in the five countries which reported data on this topic were higher than expected and may indicate that the populations of these countries are aware of the need for, and are interested in, oral healthcare. The data indicated that in Belarus, annual uptake by the population was $65 \%$, in Bulgaria and the Czech Republic $66 \%$, in Hungary $50 \%$ and in Slovenia from $67 \%$ to $86 \%$ depending on age. EU/EEA countries report annual uptake of from $40 \%$ in Austria and Iceland to $80 \%$ in Sweden 5 .

Seven Eastern European countries reported data for the percentage of Gross National Product (GNP) spent on oral healthcare in 1998. These were Belarus (0.5\%), Bosnia (1.0\%), Bulgaria (0.1\%), the Czech Republic $(0.37 \%)$, Hungary $(0.12 \%)$, Latvia $(0.05 \%)$, Slovenia $(0.62 \%)$. In the EU/EEA in 1996, the range was from $0.3 \%$ in Greece and Ireland to $0.9 \%$ in Sweden ${ }^{3}$. By themselves, the data on percentage of GNP spent on oral healthcare are of little value in that $1 \%$ of a low GNP may purchase less that $0.2 \%$ of a high GNP. However, this indicator does reflect the importance or priority given to oral healthcare in a particular country at a particular time. The reported data indicated that in 1998 only three of the Eastern European countries that responded to the CECDO survey, committed a percentage of GNP to oral healthcare which matched that of EU and EEA countries; in others the percentage was lower.

\section{Oral healthcare systems}

The Czech Republic, Hungary and Poland are the three largest countries scheduled to join the EU. Their combined population is just over 60,000,000 (about the same as that of France, Italy or the United Kingdom). Collectively, in 1998 they had almost the same number of dentists $(30,000)$ as the United Kingdom but fewer than France $(39,500)$ and Italy $(45,000)^{10}$. Their oral healthcare systems vary from each other and from those of the other Eastern European countries which reported data.

\section{Czech Republic}

In the Czech Republic oral healthcare is today predominantly private - 'based on the principle of the free choice of dentist' and upon the demand for treatment. Czechs have had obligatory oral health insurance since 1992 within the national General Health Insurance Scheme. The scheme covers $97 \%$ of children and adolescents up to 18 years of age, pensioners and $67 \%$ of the adult population. Fourteen other health insurance schemes and employees' sick funds cover the remaining $33 \%$ of adults. The National Health Insurance Scheme is identical to the other 14 
health insurance schemes and sick funds and covers the cost of oral healthcare of children up to 18 years of age, with the exception of some prosthodontics (special rules) and fixed orthodontic appliances. Basic oral healthcare of adults (an annual dental examination and calculus removal, necessary local anaesthesia, amalgam fillings, endodontics, periodontal treatment, dento-alveolar surgery, resin crowns and simple removable dentures) are fully covered by the insurance. Approximately onethird of the cost of tooth-coloured fillings and other than 'simple' prosthodontics are covered by the health insurance scheme, the rest by patients (policyholders). Implants are not covered and patients have to pay for them in full. Currently, no public oral healthcare exists in the Czech Republic. Oral healthcare of children and adolescents is provided predominantly by private dental practitioners working as 'family dentists' and partly by dentists who specialised in paediatric dentistry before 1990 .

\section{Hungary}

In Hungary the costs of the provision of oral healthcare for almost all the population are covered by one central organisation - the National Health Insurance Company. All employers and employees are obliged to pay into this insurance company. Until they are 18 years of age Hungarians receive oral healthcare free of charge, with the exception of orthodontic care which is free if begun before the age of 16 years. Patients aged between 18 and 60 years obtain oral screening, emergency treatment and oral surgery free of charge but must pay a proportion of the cost of all other treatment and $90 \%$ of the cost of treatment involving laboratory work (crowns, bridges and dentures). However, expectant mothers, those who work in the military, the chronically sick or retired people are required to pay very little towards, or are exempt from, the costs of their oral healthcare.

At the beginning of 2000 , about $50 \%$ of dentists worked as salaried employees of the National Health Insurance Scheme and the other $50 \%$ worked as independent contractors. These independent contractors may work totally privately (without the public insurance system), or in contract with the National Health Insurance Company, or both. Before the reforms nearly all dental clinics were state owned, maintained by District Governments at a local level and employing dentists on a salary. Many clinics have now been sold or rented to dentists. Privatisation is seen as a way in which to raise more money for oral healthcare. To facilitate the process, Regional Governments can make loans available to dentists.

\section{Poland}

Reforms started in Poland in 1989. Prior to this year, primary oral healthcare was provided almost exclusively in the public sector by state-owned regional dental practices, dental offices affiliated with places of employment and by school dental offices. However, there were considerable differences in access to oral healthcare, particularly between urban and rural areas due to an uneven distribution of dental personnel. For example, according to data from 1995, in some areas the number of inhabitants per dentist was $10,000^{11}$. In addition to the public dental service, funded from the state budget (ie taxes) and providing treatment free of charge, there was a small private sector providing services with the costs charged to individual patients. However, the size of the private sector was severely limited by the fact that dentists working in private practice were also obliged to work full-time in the public dental service.

Over the period 1989-1998, together with an opening up of the free market in general, there was an increase in the number of private dental practices but public clinics continued to function. Towards the end of 1992, around $80 \%$ of dentists were working in private practice at least parttime ${ }^{11}$. At this stage, setting up a private practice was not regulated by any professional body - it was sufficient to register as an 'economic venture' with the local authorities. Since 1998, registration of practices has commenced by the Chamber of Physicians, which now has to give its permission for the opening up of a new practice. Furthermore, regular nationwide monitoring of oral health was commenced in 1997 - this should indicate the treatment needs in different regions and, in the long term, provide information on the effectiveness of services provided. In 1993, a national programme of oral health promotion was introduced in the first class of primary schools as well as special preventive programmes for children from high-risk groups. The costs of this programme were covered by a national budget.

In 1999 regional sickness funds and a compulsory system of health insurance were introduced. At present, the insurance system guarantees basic services free of charge. These include:

- preventive services (check-ups, oral hygiene instruction, topical fluoride application, fissure sealing);

- curative services including emergency treatment (treatment of caries, pulpal and periapical pathology including endodontic treatment of single-rooted teeth in adults, endodontic treatment of all teeth in those aged 18 years and under, treatment of lesions of the oral mucous membrane, extractions, basic treatment of periodontal disease, basic emergency treatment of traumatized patients);

- prosthetic services (removable prostheses) and orthodontic treatment with a removable appliance for children aged 14 years and under.

Patients are free to chose a dentist from those dentists/practices that have a contract with the sickness fund. Basic care, treatment and materials used are guaranteed under the public insurance system and are specified by the Ministry of Health. However, the sickness fund operating in a given region allocates (rations) the volume of treatment which any particular dentist/practice may carry out. Any procedure or material not guaranteed by the public insurance system may be obtained privately by a co-payment from a patient, subject to availability at the practice concerned.

\section{Political pressures to 'go west'}

The fall of the 'Iron Curtain' started a major reform in the healthcare systems of the Eastern European countries which had been guided by the Soviet model and 
operated by the individual states. Economics have probably been one of the driving forces behind the reforms in the general healthcare as well as oral healthcare. In the old system oral healthcare was invariably financed from the national budget. However, in some countries this public (state) system had problems with costly equipment and materials which sometimes might have influenced the treatment standards. The salaries for dentists were low compared with Western Europe but not with other professionals and academics in the East. However, the political pressure to 'go west' and the opening of 'the market' have lead to privatisation.

The transition has been different in the individual countries depending largely on economic and political factors. The move from salaried (public) employment to private practice has been more rapid in the former Eastern Germany and Poland than in Hungary and Slovenia. In the former East Germany, $88 \%$ of dentists had moved from salaried employment into private practices by the end of $1992^{1}$. In other countries the pace of change has been slower. There is still substantial public provision of oral healthcare for many sections of the community, including children and the elderly, in many Eastern European countries. Some countries have established an insurance system, with or without co-payment by patients and others have no sickness insurance systems. Due to underdeveloped or a lack of established insurance systems most people in the former USSR countries, ie Russia and Belarus, still use the public oral healthcare clinics where some care is provided free of charge. However, the level of care is limited by a shortage of financial and other resources. In order to obtain a wider choice of treatment and materials, patients have to pay even within the public system.

In conclusion, there have been major changes in the systems for the provision of oral healthcare in the Eastern European countries. Many of them seem to have adopted a Bismarckian model ${ }^{3}$ with a sickness insurance system that covers part of the costs. In this respect they have drawn nearer to the systems in Germany, France, Austria and Belgium.

\section{Acknowledgements}

The authors wish to thank all those who responded to the 1998 CECDO survey and to Dr Vago and Professor Banoczy for providing descriptions of the oral healthcare system in Hungary.

1. Schriftreihe des Bundesministers für Gesundheit. Daten des Gesundheitswesens, Band 91. Nomos Verlagsgesellschaft, BadenBaden 1999.
2. European Council Directives Numbers 78/686/EEC and 78/687/EEC. Official Journal of the European Communities 1978 ; 21 : L233, ISSN 0378-6978.

3. Widström E, Eaton K. Systems for the Provision of Oral Health Care, Workforce and Costs in the EU and EEA. National Research and Development Centre for Welfare and Health, STAKES. Saarijärvi (Finland) 1999.

4. Widström E, Eaton K, van den Heuvel J. Dentistry in the EU and EEA. National Research and Development Centre for Welfare and Health, STAKES. Helsinki 1996.

5. Bratthall D, Hänsel Pettersson G, Sundberg H Reasons for caries decline: what do the experts believe? Eur J Oral Sci 1996; 104:416-22.

6. Pettersson H G, Bratthall D. The caries decline: a review of reviews. Eur J Oral Sci 1996; 104:436-43.

7. Kuusela S, Honkala E, Kannas L, Tynjälä J, Wold B. Oral hygiene habits of 11-year-old schoolchildren in 22 European countries and Canada in 1993 - 1994. J Dent Res 1997;76:1602-9.

8. Paeglitis A. The tasks, roles and challenges of the Latvian Chief Dental Officer. Council of European Chief Dental Officers, Looking into next millenium. Papers and abstracts 25-27 November, 1999. Themes 5:9-11. National Research and Development Centre for Welfare and Health, Helsinki 1999.

9. Vrbic V. Oral Health in Slovenia, 1987- 1993. Community Dent Oral Epidemiol 1996; 24:364-5.

10. Council of European Chief Dental Officers (CECDO). Unpublished data from 1998. London 1999.

11. Wierzbicka M, Adamowicz-Klepalska B, Piekarczyk J, Pisulska-Otremba A, Spiechowicz E, Zietek M: Narodowy program ochrony narzadu zucia Wokresie 1997-2001. Czasopismo Stomatologiczne, 1999; LII, 4:271-81. 